Eketahuna, Greytown and Carterton. Property in Wellington and Palmerston North was damaged. At the southern end of the North Island, therefore, extensive minor damage was done over a wide area, windows being broken, chimneys dislodged and so forth, though no casualties have been reported. Buildings erected since 1933 under the earthquake by-laws (similar to those in force in many parts of California), have suffered only superficial damage. The main shock was preceded by a precursor shock at 8.15 p.m. (local time). The principal shock is said to have been the most severe since February 1931, when more than two hundred people were killed in the Hawke's Bay region as the result of a very severe earthquake. New Zealand is a seismic region, and hundreds of minor shocks occur every year. The study of these, and the multitude of seismological problems which arise, is actively pursued at Wellington, and we await further news of the present shock from the Dominion Observatory.

During March 1942, nine distant earthquakes were registered by the seismographs at Wellington, Auckland, Christchurch and Arapuni in New Zealand, according to the seismological bulletin just received from the Dominion Observatory, Wellington. The greatest appears to have been on March 5, when the ground movement at Wellington was $3 \mathrm{~mm}$. downwards, and the shock is estimated to have had its epicentre some $82^{\circ}$ from Wellington with a focus rather deeper than normal. The shock was recorded at Wellington at $20 \mathrm{~h} .00 \mathrm{~m}$. 51s. U.T. Microseisms interfered with the registration and the interpretation of the records throughout the month.

Additionally, 21 local earthquakes were recorded. The greatest was of intensity 6 on the Rossi-Forel scale (ringing of bells, stopping of clocks, visible disturbance of trees and shrubs, etc.), which occurred on March 25 at $15 \mathrm{~h} .49 \cdot 6 \mathrm{~m}$. U.T. and was felt at Milford Sound and Queenstown. Six subsequent shocks were felt in the same area though they were of lesser intensity. Other areas affected by earthquake activity were Opotiki (March 2), Motu (March 3 and 5), Pipiriki and Whangamomona (March 5, 6, 10, 12, 16 and 18), Napier and Hastings (March 20), and Te Whaiti and Taupo (March 22). Focal depths of these local earthquakes have been estimated to range from normal (about $16 \mathrm{~km}$.) to $100 \mathrm{~km}$. The bulletin is stated to be provisional, but it contains much useful data.

\section{Colour of Machines and Workshop Efficiency}

UNDER the title "Color for Efficiency", Matt Denning and Arthur A. Brainerd have described experiments made in an American machine shop by re-painting the machines in pale colours (Product Engineering, Jan., 1942). Machines are usually painted black or battleship grey, and their surfaces thus have a low reflexion factor. There is often too little brightness of colour contrast between the work and parts of machines forming its background. If these parts are finished with light-coloured paint, contrast is improved, and the work made easier to see. Moreover, the illumination of the work itself may be improved by light reflected from machine surfaces. The whole machine may be painted a uniform colour, or a different, but also pale, colour can be used for parts not in close proximity to the work. The general brightness of a machine shop is enhanced by this treatment. Where high machines, such as heavy presses, are used, a high reflectivity of their superstructure means that more light is reflected to adjacent machines, and troublesume shadows may be avoided. The colours tested were ranked on the results of a work-time study and on opinions of machine operators and measurements of reflexion factors. Light buff proved best, then aluminium and light grey. Yellow was found to be tiring. In Great Britain, the advantages of painting machines a light colour were recognized by the Departmental Committee on Factory Lighting, which recommended this practice in its fifth report, published in 1940 ; recent trials here have proved very satisfactory.

\section{Hormone Sprays for Fruit}

THE recent rapid developments in the investigation of growth-promoting substances have been closely followed by widespread attempts to apply the socalled plant hormones in horticultural practice. The use of synthetic growth substances to facilitate the rooting of cuttings became a craze almost overnight, and there is no doubt that remarkable results were achieved in many cases. There are still, however, species which resist all attempts to make them produce roots readily enough to make this method of propagation practicable on a commercial scale.

Other uses for growth substances have now become the centre of interest, and these form the subject of a review in the American Fruit Grower of June 1941. Perhaps the most successful application has been the use of naphthalene acetic acid and naphthalene acetamide to control the pre-harvest drop of apples. Spraying with dilute solutions of these substances, by delaying the formation of the abscission layer, enables fruits to be kept on the tree until a desirable degree of colour and maturity is reached. Fruit dropping from pears, plums, apricots, oranges and cherries has also been reduced, and, in the case of the latter, the sprayed fruits showed a lower acid and higher sugar content than the controls. Satisfactory results with some English varieties of apple have been obtained by similar methods at the East Malling and Long Ashton Research Stations. The method appears to be of particular value in com. bating the effects of strong winds. Also of interest is the checking of bud development by hormone sprays. By this means the risk of frost injury to fruit blossoms in spring may be reduced. Indole butyric acid, applied unilaterally to growing shoots of young apple trees, causes more rapid growth on the treated side. By this means the development of narrowangled and therefore structurally weak crotches can be avoided.

\section{Porcelain Insulators}

WrItring in the Electrical Review of June 12, 1942, on the design of electrical insulators in relation to manufacturing processes, Dr. E. Rosenthal points out that methods of shaping ceramic materials are based on the plastic quality of the china clay and ball clay in the case of porcelain, and of clay, talcum or bentonite in the case of certain ceramics. The plasticity of ceramic materials is caused by the adsorption of water at the surface of the kaolinite crystals forming the china and ball clays, this water surrounding the clay molecule. The forces which attract the water to the molecules and crystals are electrical in origin and impart to the clay molecules their colloidal and plastic nature. The hygroscopic water and the "water of formation" form the colloidal gels which give to the clay particles their plastic 
characteristics. All ceramic plastic materials also contain chemically combined water of crystallization. Although ceramic articles can easily be shaped as a result of the plasticity of their raw materials, the finished materials owe their physical and mechanical properties to the crystals and to the glass matrix formed during firing at high temperatures.

In contradistinction to ceramic plastic raw materials, the plasticity of organic plastics is not caused by water but by the long chains of carbon atoms or arrangements of carbon atoms with other elements of which their molecules consist. These chains are arranged in various forms, such as long bundles or micelles and in tangled masses composed of threads. During manufacture plastic organic materials are transformed by heat (or by heat and pressure) into a non-plastic state, nothing being evaporated. Only the structure of the big molecules is altered and as only very small shrinkage occurs greater accuracy in certain shapes can be obtained from organic-plastic than from ceramic materials. Incidentally, the molecules of ceramic plastics are built up of silicon compounds, whereas those of the organic plastics are built up of carbon compoundsan instance of the many similarities of these two elements. With organic plastics, transformation from the plastic to the non-plastic form which gives the materials their mechanical and electrical characteristics takes place at about $180^{\circ} \mathrm{C}$. In the case of ceramics the formation of the crystals and the glass matrix, which imparts these characteristics, takes place between $1,300^{\circ}$ and $1,400^{\circ} \mathrm{C}$.

The difference between the manufacture of ceramic and other materials, such as metal parts and organice plastic materials, is therefore that the article is not shaped from ready-made material but has first to be prepared from various plastic and non-plastic substances. After the water is removed in a filter press the body is homogenized, and out of this body the article is shaped into the desired form which is then dried and glazed and subjected to very high tem. peratures for final formation. 'The methods of manufacturing porcelain and low-loss ceramic articles containing talcum are very similar. The article proceeds to a description of the various processes employed in the commercial production of porcelain insulators.

\section{Stellar Structure}

A PAPER on stellar structure appears in the Observatory of May, in which Dr. T. G. Cowling gives a brief summary of the work of various physicists on the theory of stellar structure during the past ten years. A large portion of the paper is devoted to recent developments in the physical theory of the generation of stellar energy. The work of Gamow, Weiszäcker and Bethe has shown that the most probable mode of generation of energy is by the transmutation of hydrogen into helium, atoms of carbon and nitrogen acting as catalysts in the reaction. Assuming that the temperature at the centre of a star is about $20,000,000^{\circ} \mathrm{K}$., increasing temperature implies increasing rate of generation of energyapproximately as the seventeenth power of the temperature-and the popular idea was that instability of the star would ensue. This view is erroneous because the generation of energy does not affect the internal temperature for a period of the order of a million years, and in this time the star can adjust itself so as to dispose of the extra energy.

It has been argued that reaction between energy generation and temperature would produce radial oscillations, such as are observed in the Cepheids, but how can their absence in other stars be explained? A possible explanation may be found in the time-lag between increase in temperature and the resulting increase in generation. Another explanation given by Cowling is that a very large dissipation of the energy of an oscillation takes place in the outer layers of a star, but this dissipation is so large that it is difficult to understand why Cepheids continue to oscillate. Eddington believes that the dissipation in their outer layers is very low because of the changes in hydrogen ionization during the oscillation. On the whole, therefore, there are no objections on astrophysical grounds to the view that the energy of a star is nearly all generated in the hottest central part. Other matters considered include the KelvinHelmholtz hypothesis that stars radiate because gravitational energy is liberated as they contract, and observational evidence regarding the internal state of eclipsing binaries.

\section{The University of London}

ThE title of professor emeritus of anatomy in the University has been conferred on Prof. J. E. S. Frazer, who resigned from the University professorship of anatomy at St. Mary's Hospital Medical School in March 1940. The title of reader in geography in the University has been conferred on Dr. S. W. Wooldridge, in respect of the post held by him at King's College.

The degree of D.Sc. has been conferred on Prof. R. V. Christie, University professor at St. Bartholomew's Hospital Medical College ; Mr. Frank Dickens, of the Imperial College of Science and Technology; Mr. Charles Potter, of the Imperial College of Science and Technology; Mr. E. E. L. Dixon, an external student; and Mr. C. E. Lucas, an external student.

\section{The University of the Philippines}

Fears were expressed, in the early days of the invasion by the Japanese of the Philippines when the open city of Manila was bombed, that the University and other colleges of the city, some of them of great antiquity, might have been damaged or destroyed. It is therefore welcome news to learn that no damage of any kind has been suffered by the buildings of the University of the Philippines or, apparently, by other educational institutions. The bombing was concentrated on a small area in another part of the city.

\section{Announcements}

Archbishop Lord Lang of Lambeth and Sir Charles Sherrington have been elected trustees of the British Museum.

Sir Henry Dale, president of the Royal Society, has been appointed chairman of the Science Committee of the British Council, in succession to the late Sir William Bragg.

Dr. F. W. Hardman and Mr. W. P. D. Stebbing, in two articles in Archoeologix Cantiana (53 and 54), have outlined the history of Stonar and the Wantsum channel. As the prosperity of the place depended entirely on the state of the channel, this is discussed at some length in the first article. While the matter is primarily of interest to the local antiquary, there are aspects which make it of wider importance.

Erratum. Nature, May 23, p. 584, col. 2, line 3 of second complete paragraph : before words "striking force" insert "the effect of". 